\title{
An Improved Numerical Model of Shield Tunnel with Double Lining and Its Applications
}

\author{
Qi-xiang Yan, Chao-fan Yao, Wen-bo Yang, Chuan He, and Ping Geng \\ MOE Key Laboratory of Transportation Tunnel Engineering, Southwest Jiaotong University, Chengdu 610031, China \\ Correspondence should be addressed to Ping Geng; gengp@scjm.gov.cn
}

Received 3 May 2015; Accepted 11 August 2015

Academic Editor: Santiago Garcia-Granda

Copyright ( 2015 Qi-xiang Yan et al. This is an open access article distributed under the Creative Commons Attribution License, which permits unrestricted use, distribution, and reproduction in any medium, provided the original work is properly cited.

\begin{abstract}
Based on the existing numerical models of shield tunnel with double lining, an improved numerical model is developed and its rationality is verified by a similar model test. In the improved numerical model, lining, joint, and junction surface, respectively, are simulated by beam, spring, and a combination of compression bar and spring. Through the comparison of the numerical analysis results of the improved model and existing models, it turns out that the defects or problems in the existing numerical models are resolved; tension appearance on the contact surface and junction surface and the abrupt change of bending moment in linings are solved in the improved model because the compression bar element and the coupling technology of node displacement in the junction surface is applied. Therefore, the improved numerical model could be applied to analyze double lining with waterproof on the junction surface and separation of the junction surface under an unfavorable load. In this paper, the parameter formulas of element stiffness, applicable to the junction surface and contact surface of double lining, are given definitely, and the influence of the element amount of junction surface on the analysis results is discussed. Based on the improved numerical model, the mechanical behavior of the double lining of the Huangpu River Tunnel in China is studied, and some conclusions are obtained as follows. (1) The thickness increase of the double lining will clearly increase its bending moment, but it has little influence on its axial force. (2) The allocation proportion of the bending moment between the segment lining and secondary lining has no linear relationship with the ratio of the lining thickness.
\end{abstract}

\section{Introduction}

Double lining is a kind of tunnel structure composed of an outer segment lining and an inner cast-in-place concrete secondary lining formed after tunnel boring machine installation of a segment lining, as shown in Figure 1. As the double lining structure has advantages with respect to structure strengthening, anticollision, water proof strengthening, tunnel inner surface smoothing, tunnel S-shape correction, vibration absorption, and settlement resistance, many shield tunnels with double lining have appeared worldwide with the spread of tunnel boring machine technology. For example, the primary lining of a Dradenau sewer syphon tunnel in Hamburg is segment lining, and its secondary lining is castin-place concrete [1]. A tunnel whose external and internal diameters are 13.9 meters and 11.9 meters was constructed beneath a street carrying heavy traffic in the vicinity of Nishi-Shinjuku: its segment lining thickness is 0.7 meters and a secondary lining thickness is 0.3 meters [2]. The cracking in the extension shield tunnel of the blue metro line in Lisbon, Portugal, eventually led to corrosion of the rebar due to the marine environment, and the capacity of the tunnel would decrease in the long term, leading to a substantial risk of instability. For this reason, a secondary lining was constructed inside the existing tunnel as a durable remedial measure [3]. Shiziyang undersea tunnel of the Guangzhou-Shenzhen-Hong Kong express rail link in China has a segment lining of 0.5 meters and a secondary lining of 0.2 meters [4]. The Trans-Tokyo Bay highway tunnel, which is subjected to extremely soft strata under the sea, extremely high water pressure, and active seismic conditions in the Tokyo Bay area, has a large external diameter of the primary lining (approximately $14 \mathrm{~m}$ ). To ensure the safety of the Trans-Tokyo Bay highway tunnel, a secondary lining inside with a thickness of $35 \mathrm{~cm}$ and segment lining with a thickness of $65 \mathrm{~cm}$ were applied [5]. As there are more and 


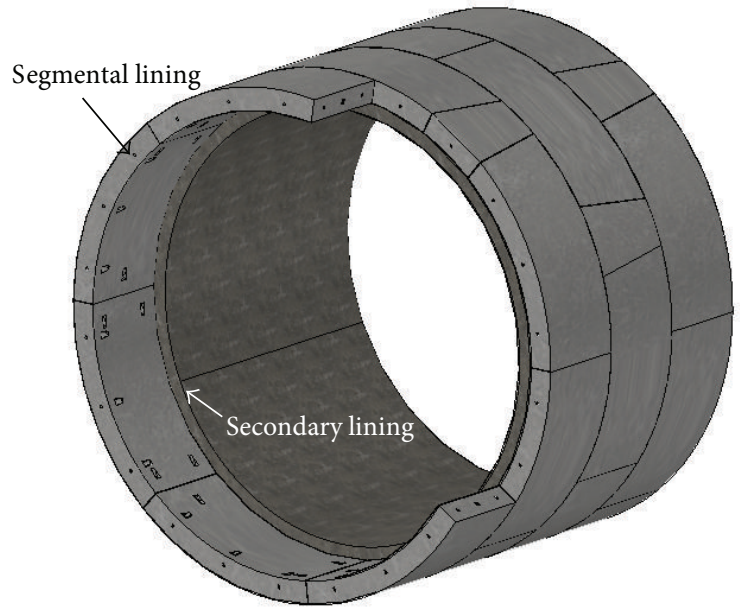

FIGURE 1: Sketch of shield tunnel with double lining.

more underwater railway tunnels crossing rivers or seas in China, the application of double lining will become more frequent. The Huangpu River Tunnel in Shanghai-Nantong Railway, the Qiantang River Tunnel in Hangzhou-Changsha Railway, and the Qiongzhou Strait Tunnel from Zhanjiang to Haikou all will adopt the shield tunnel with double lining [6].

The researches on shield tunnel mainly focus on single lining tunnel. Do et al. [7] applied a numerical study, which has been performed under seismic circumstance, to investigate the factors that affect segmental tunnel lining behavior. Gomes [8] examined the effect of the stress disturbance induced by tunnel construction on the completed tunnel's seismic response. El Naggar et al. [9] developed an analytical procedure for evaluating in-plane moments and thrusts in composite and jointed tunnel linings during earthquakes.

Some researchers also studied the behaviour of double lining structures. Murakami and Koizumi [10] investigated the behavior of shield tunnels reinforced by secondary lining, based on experiment results. Test models were composed of notched steel rings with mortar cast-in-place to their interiors. Based on the results, analytic models for double lining structures were proposed. Takamatsu et al. [11] used tests and analyses to investigate the behavior in the longitudinal direction of shield tunnels provided with secondary linings. Through studying a structural model for the evaluation of behavior in the longitudinal direction, confirmation of the validity of the structural model and a rational design method for shield tunnels with secondary linings were proposed. It was clarified that the member forces acting on the linings could be reduced by creating joints at appropriate positions on the secondary linings. Zhang et al. [12] suggested three joint interaction models corresponding to different forms of joint between primary and secondary linings and it was recommended that the coupling between primary and secondary linings must be reinforced, forming an integrated structure to bear the external pressure in the design of engineering.

The existing double lining models have some defects: no analytic model for the above-mentioned design is so scientific that it is widely recognized and adopted. ITA's (International Tunneling Association) Guidelines [13] for the design of shield tunnel lining (draft) do not involve the problems of double lining. Within China, there is usually one rough guiding principle for design: when there is enough shear resisting strength between the layers of double lining, it can be calculated as a whole structure and otherwise calculated as a composites plate only transmitting radial pressure. But no specific analysis model and calculating method are recommended for the design of double lining [14]. Therefore, on the basis of some existing double lining models, it is necessary to propose an improved double lining analysis model which can overcome some existing defects as far as possible. At present, the existing numerical models [1012] of double lining mainly include Model I, Model II, and Model III, which are based on the two-dimensional beamspring model and can be seen in Figure 2. The common characteristics of the three models are that the segment lining and secondary lining all adopt a beam element to simulate, the segment joint uses a spring element, and the contact surface between the segment lining and ground (hereinafter referred to as contact surface) employs radial spring element and tangential spring element to simulate. As all of these three models employ a radial spring element in the contact surface, radial tension will inevitably appear at the contact surface.

The difference between these three models lies in the junction surface between the segment lining and the secondary lining (hereinafter referred to as the junction surface). In Model I, a radial beam element is used to simulate the transmission of the stress between the segment lining and secondary lining. Two nodes of the beam element are fixed in the beam element of the segment lining and secondary lining, respectively, which will lead to an abrupt change in the bending moment at the fixing point of the segment lining or secondary lining. Meanwhile, radial tension that does not conform to the fact will appear in this radial beam. In Model II, the radial spring was adopted in the junction surface, which could not avoid the appearance of radial tension in the junction surface as well. In Model III, a contact friction element was employed to simulate the force transfer on the junction surface. Its feature is that the tangential force value on junction surface is in direct proportion to the radial force and friction coefficient, which could not reflect the relationship between the tangential force and tangential relative displacement. Moreover, as there is no experimental data, the friction coefficient value of the junction surface is difficult to determine.

In conclusion, the defects of the three models mentioned above are mainly as follows: the appearance of radial tension on the junction surface and the contact surface, an abrupt change in the bending moment, discordance of the radial force, and radial displacement of junction surface, in addition to evidence deficiency of friction coefficient determination. These defects would greatly limit the application of the models mentioned above in specific engineering. Aiming at these aforementioned defects, some improvements of the numerical model are conducted. A model of lining, joint, and junction surface, respectively, simulated by beam, spring, and combination of compression bar and spring is put forward 

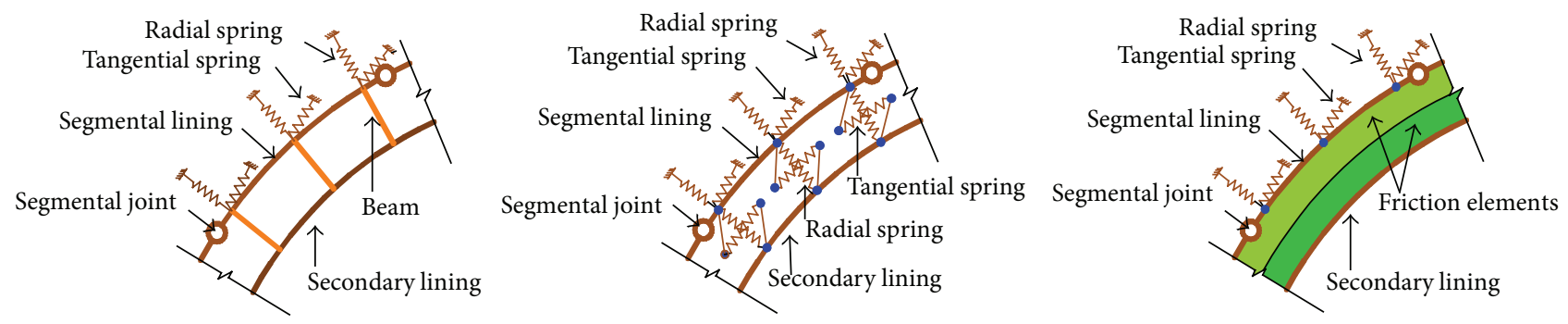

FIGURE 2: Present numerical models of shield tunnel with double linings.

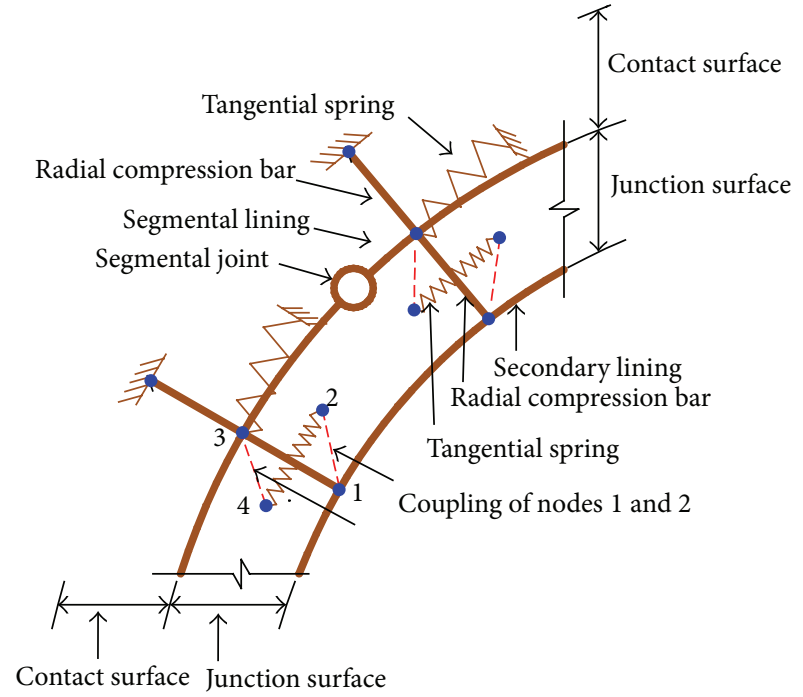

(a) Junction surface and contact surface

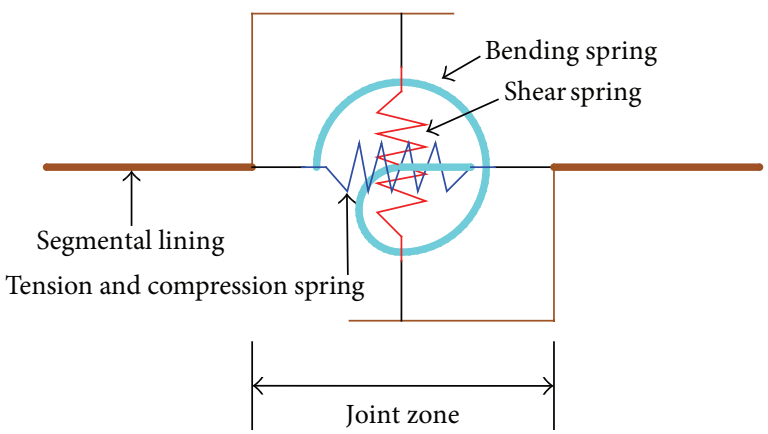

(b) Segmental joint

FIgURE 3: Improved model.

to solve problems. Furthermore, the number of junction surface elements and their stiffness are discussed. Secondly, model tests are conducted to verify the improved model, and the comparison between the improved model and existing numerical models reveals the advantages of the improved model. Finally, the mechanical behavior of the Qiantang River Shield Tunnel with double lining in the HangzhouChangsha Railway in China is studied in terms of the improved model.

\section{The Improved Numerical Model and Method}

2.1. The Improved Numerical Model for Shield Tunnel with Double Lining. To overcome the defects of the aforementioned models, an improved model, whose lining, joint, and junction surface are, respectively, simulated by beam, spring, and a combination of compression bar and spring, is put forward, as shown in Figure 3. The bar element bearing compression, which moves perpendicular with junction surface, is used only to simulate the radial force transmission on the contact surface and the junction surface. When the compression bar element is in tension, its axial force becomes zero naturally, so that the problem that radial tension appears on contact surface and junction surface can be solved. The coupled tangential spring, which runs parallel to the junction surface, could be used to extract the displacement of the segment lining node and its corresponding secondary lining node in the tangential direction to the two ends of the tangential spring. With extracted tangential displacement and calculated stiffness, the coupled tangential spring could simulate the tangential force transmission on the junction surface, so as to solve the problem that the tangential force and tangential displacement are unrelated to each other in Model III: see Figure 3(a). As the junction surface is simulated by the hinged radial compression bar and the tangential spring, both of which are unidirectional stress elements, it avoids the appearance of the abrupt change phenomenon of bending moment caused by the fixed beam element in Model I. The tension and compression spring, shear spring, and bend spring are set in the position of the segmental joint to simulate the passing of forces in every direction: see Figure 3(b). The comparison of the improved model and the existing three models can be seen in Table 1.

2.2. Stiffness of Junction Surface and Contact Surface in Improved Model. The problem of the parameter value to choose relates to the lack of theory evidence in Model III. 
TABLE 1: Comparison of elements between improved model and existing models.

\begin{tabular}{|c|c|c|c|c|}
\hline Items & $\begin{array}{l}\text { Segment lining and } \\
\text { secondary lining }\end{array}$ & Segment lining joint & Junction surface & Contact surface \\
\hline Model I & Beam element & $\begin{array}{l}\text { Spring elements with } \\
\text { functions of tension and } \\
\text { compression, shear, and } \\
\text { bending resistance }\end{array}$ & Fixed radial beam element & $\begin{array}{l}\text { Radial and tangential } \\
\text { spring elements with } \\
\text { functions of tension and } \\
\text { compression resistance }\end{array}$ \\
\hline Model II & Beam element & $\begin{array}{l}\text { Spring elements with } \\
\text { functions of tension and } \\
\text { compression, shear, and } \\
\text { bending resistance }\end{array}$ & $\begin{array}{l}\text { Radial and tangential } \\
\text { spring elements with } \\
\text { function of tension and } \\
\text { compression resistance }\end{array}$ & $\begin{array}{l}\text { Radial and tangential } \\
\text { spring elements with } \\
\text { functions of tension and } \\
\text { compression resistance }\end{array}$ \\
\hline Model III & Beam element & $\begin{array}{l}\text { Spring elements with } \\
\text { functions of tension and } \\
\text { compression, shear, and } \\
\text { bending resistance }\end{array}$ & Friction elements & $\begin{array}{l}\text { Radial and tangential } \\
\text { spring elements with } \\
\text { functions of tension and } \\
\text { compression resistance }\end{array}$ \\
\hline Improved model & Beam element & $\begin{array}{l}\text { Spring elements of node } \\
\text { displacement coupling with } \\
\text { functions of tension and } \\
\text { compression, shear, and } \\
\text { bending resistance }\end{array}$ & $\begin{array}{l}\text { Radial compression bar } \\
\text { with functions of } \\
\text { compression resistance and } \\
\text { tangential spring with } \\
\text { coupling functions of } \\
\text { elements node } \\
\text { displacement }\end{array}$ & $\begin{array}{l}\text { Radial compression bar } \\
\text { with functions of } \\
\text { compression resistance and } \\
\text { tangential spring element }\end{array}$ \\
\hline
\end{tabular}

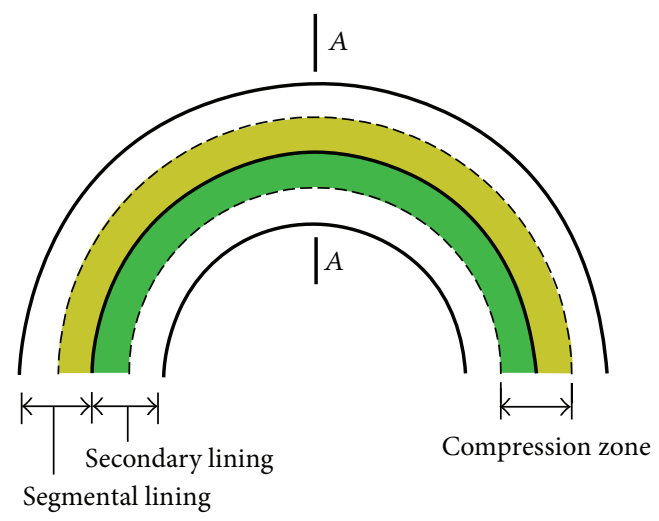

(a) Cross section

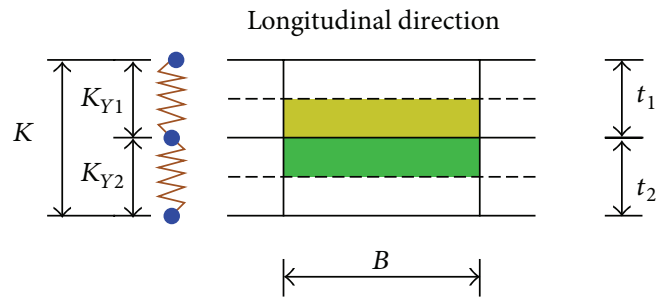

(b) $A-A$ section

FIGURE 4: Compression stiffness calculation schematic diagram of junction surface.

The improved model learns from the existing research results $[15,16]$ and gives the following calculation methods of the radial and tangential stiffness of the junction surface and the contact surface.

(1) Stiffness of junction surface: after the segment lining is assembled, the secondary lining is manufactured by castin-place concrete directly. Double lining can be taken as a superimposition lining structure, and its radial compression can be simplified as the mechanical model shown as in Figure 4 . In the figure, $B$ is the width of single segment lining in the longitudinal direction. Supposing that the compression stiffness between the layers is equal to the compression stiffness of the concrete column in the compression section, which has half thickness of the interior lining and external lining, the compression stiffness in the compression section of the interior lining and the external lining is as follows:

$$
\begin{aligned}
& K_{Y 1}=\frac{E_{1} \times A}{t_{1}^{\prime}}=\frac{2 E_{1} \times A}{t_{1}}, \\
& K_{Y 2}=\frac{E_{2} \times A}{t_{2}^{\prime}}=\frac{2 E_{2} \times A}{t_{2}} .
\end{aligned}
$$

In the formulas, $K_{Y 1}$ and $K_{Y 2}$ represent the compression stiffness of the segment lining and secondary lining, respectively, $\mathrm{kN} / \mathrm{m} ; E_{1}$ and $E_{2}$ represent the elasticity modules of concrete in the segment lining and secondary lining, respectively, $\mathrm{kN} / \mathrm{m}^{2} ; t_{1}$ and $t_{2}$ represent the thickness of the segment lining and secondary lining, respectively, $\mathrm{m} ; t_{1}^{\prime}$ and 


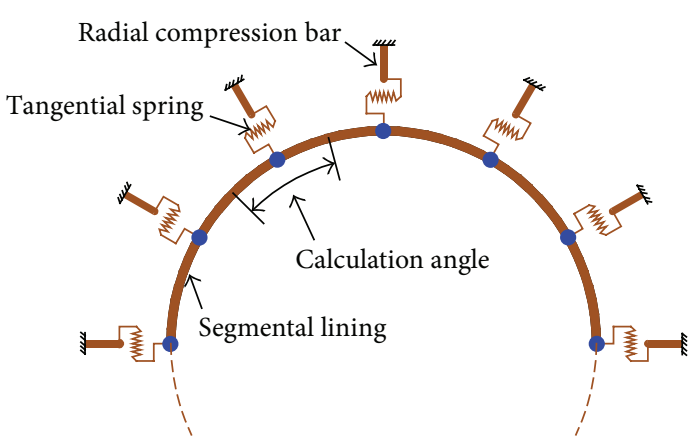

(a) Mechanical model of contact surface

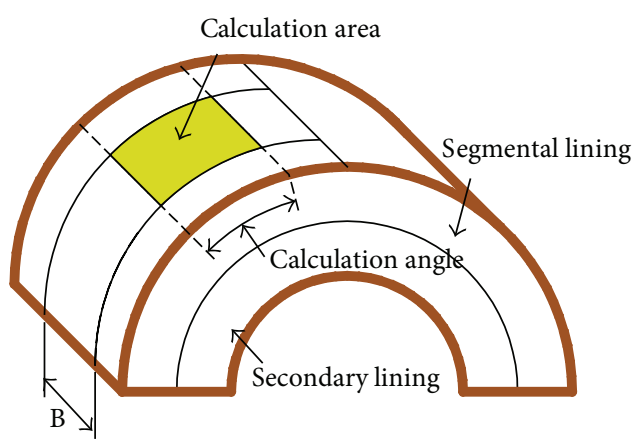

(b) Calculation area

FIGURE 5: Schematic diagram of calculation model of contact face between segment and strata.

$t_{2}^{\prime}$ represent the thickness of the compression zone in the segment lining and secondary lining, respectively, $\mathrm{m}$; $A$ is the corresponding area of single radial compression bar element in the junction surface: $A=B \times \theta \times R_{H}, \mathrm{~m}^{2} ; B$ is the width of the single segment lining in the longitudinal direction, $\mathrm{m} ; \theta$ is the corresponding calculating angle of the single compression bar element in the junction surface; $R_{H}$ is the radius of the junction surface, $\mathrm{m}$.

Combine Formulas (1a) and (1b), according to the calculating formula of spring in series stiffness coefficient: that is,

$$
K_{Y}=\frac{K_{Y 1} \times K_{Y 2}}{K_{Y 1}+K_{Y 2}}=\frac{2 E_{1} E_{2} A}{E_{1} t_{2}+E_{2} t_{1}} .
$$

In the formula, $K_{Y}$ is the radial compression stiffness of a single compression bar in the junction surface, $\mathrm{kN} / \mathrm{m}$.

The junction surface tangential relationship is similar to the radial relationship, and the tangential stiffness of the double lining is as follows:

$$
\begin{aligned}
K_{T 1} & =\frac{G_{1} \times A}{t_{1}^{\prime}}=\frac{2 G_{1} \times A}{t_{1}}, \\
K_{T 2} & =\frac{G_{2} \times A}{t_{2}^{\prime}}=\frac{2 G_{2} \times A}{t_{2}}, \\
K_{T} & =\frac{K_{T 1} \times K_{T 2}}{K_{T 1}+K_{T 2}}=\frac{2 G_{1} G_{2} A}{G_{1} t_{2}+G_{2} t_{1}} .
\end{aligned}
$$

In the formula, $K_{T}$ is the tangential stiffness of a single tangential spring in the junction surface, $\mathrm{kN} / \mathrm{m} ; K_{T 1}$ and $K_{T 2}$ represent the tangential shear stiffness of the segment lining and secondary lining, respectively, $\mathrm{kN} / \mathrm{m} ; G_{1}$ and $G_{2}$ represent the shear modulus of concrete in the segment lining and secondary lining, respectively, $\mathrm{kN} / \mathrm{m}^{2}$.

(2) Stiffness of contact surface: the calculating model of the contact surface is shown as in Figure 5. As the segment lining stiffness is far larger than that of stratum, it can be considered that the segment lining stiffness has no influence on the stiffness of the contact surface approximately. The radial stiffness of a single compression bar at the contact surface can be presented as

$$
K_{R}=k_{r} \times A^{\prime} .
$$

In the formula, $K_{R}$ is the radial stiffness of single compression bar, $\mathrm{kN} / \mathrm{m} ; k_{r}$ is the radial resistance coefficient of stratum, $\mathrm{kN} / \mathrm{m}^{3} ; A^{\prime}$ is the area corresponding to a single radial compression bar element at the contact surface: $A^{\prime}=B \times$ $\theta^{\prime} \times R_{w}, \mathrm{~m}^{2} ; \theta^{\prime}$ is the calculating angle of a single radial compression bar element at the contact surface; $R_{w}$ is the external radius of the segment lining.

According to the experience of Japan, the contact surface tangential stiffness is approximately half the radial stiffness [5].

\subsection{Comparison between Numerical Simulation and Experi-} mental Test. To verify the rationality of the improved model and compare the advantages and defects of the existing numerical models, the shield tunnel-ground complex simulation equipment is employed to conduct the model experiment on the Shiziyang Tunnel in China with double lining. Without water pressure, the test results with the numerical analysis results of the aforementioned Model I and Model II in the same load and same structure parameters are compared.

2.3.1. Experimental Subject. The double lining section of the Shiziyang Tunnel in Guangzhou-Shenzhen railway, which is buried at the depth of $35.35 \mathrm{~m}$, is taken as the prototype structure. The external and internal radiuses of the tunnel structure are $10.8 \mathrm{~m}$ and $9.4 \mathrm{~m}$, and the thicknesses of the segment lining and the secondary lining are $0.5 \mathrm{~m}$ and $0.2 \mathrm{~m}$. The width of the single segment lining in the longitudinal direction is $2.0 \mathrm{~m}$. The segment lining is assembled with a staggered joint, and " $7+1$ " block divided mode is employed, which can be seen in Figure 6. The central angle of the key block is $16.37^{\circ}$, and the central angle of the 2 adjacent blocks and 5 standard blocks is $49.09^{\circ}$. The calculation section of this tunnel mainly crosses argillaceous siltstone stratum.

2.3.2. Experimental Device. The tunnel-ground complex simulation equipment is a plane strain loading device of a shield tunnel, which mainly includes three parts: a hydraulic loading unit, stratum and structural body, and signal collection transaction and analysis apparatus. The whole test platform's length, height, and width are $6.0 \mathrm{~m} \times 6.0 \mathrm{~m} \times 2.55 \mathrm{~m}$, and the tunnel model and model soil around it are put inside 


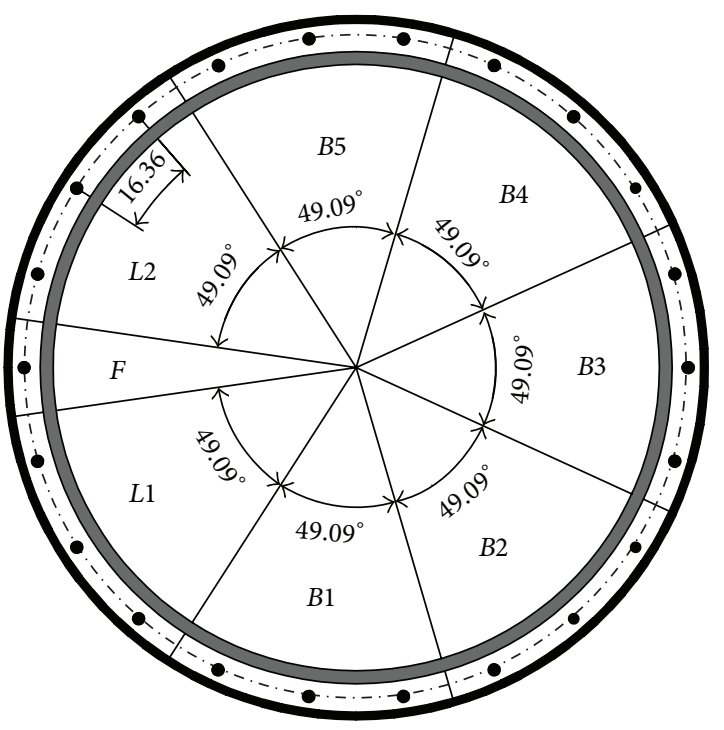

FIgURE 6: Double lining of Shiziyang Tunnel.

the device. The available filling range of the model soil is $3.0 \mathrm{~m} \times 3.0 \mathrm{~m} \times 0.2 \mathrm{~m}$, as shown in Figure 6. The loading panel is set in the vertical direction of the tunnel crossing section (direction $Z$ ), and the vertical pressure increased to the loading panel through the jack to guarantee the tunnel at the plane strain state. Horizon directions $X$ and $Y$ are set appositional to the jack, respectively, and make some impact on the removable baffle. Through the force transfer device the needed load is added to direction $X$ (simulated horizon soil pressure) and direction $Y$ (simulated vertical soil pressure). The schematic diagram of the experiment device and physical device is shown in Figures 7 and 8.

2.3.3. Method. The test takes the 1:20 geometric similarity ratio and $1: 1$ bulk density similarity ratio as the basic similarity ratios. According to the elastic similarity theory, Poisson's ratio and strain and the internal friction angle similarity ratio can be deduced as $C_{\mu}=C_{\varepsilon}=C_{\phi}=1$, as well as the strength, stress, cohesion, and elastic modulus similarity ratio $C_{R}=C_{\sigma}=C_{c}=C_{E}=20$. The model soil is filled around the double lining model and passes horizontal jack output to the double lining model through the model soil. The similarity model satisfies the similarity relationship mainly in the following aspects: the ground cohesion, compression modulus, internal friction angle and bulk density, the uniaxial compressive strength of the segment lining, double lining and elastic modulus, and the equivalent tensile (compression) strength of main reinforcement.

The model stratum employs a mixture made of barite powder, fly ash, river sand, coarse quartz, fine quartz, rosin, and oil with the specific ratio, and the mass ratio is $1: 0.341: 0.676: 0.334: 0.334: 0.08: 0.14$. The mechanical properties of the argillaceous siltstone stratum prototype and its model material can be seen in Table 2 .

The material of the segment lining is C50 reinforced concrete, and the concrete model adopts the composite
TABLE 2: Parameters of argillaceous siltstone strata in model and prototype.

\begin{tabular}{lcccc}
\hline Name & $\begin{array}{c}\text { Cohesion } \\
c / \mathrm{kPa}\end{array}$ & $\begin{array}{c}\text { Internal } \\
\text { friction } \\
\text { angle } \phi /\left(^{\circ}\right)\end{array}$ & $\begin{array}{c}\text { Model } \\
\text { elastic } \\
\text { quantity } \\
E / \mathrm{MPa}\end{array}$ & $\begin{array}{c}\text { Bulk density } \\
\gamma /\left(\mathrm{kN} \cdot \mathrm{m}^{-3}\right)\end{array}$ \\
\hline $\begin{array}{l}\text { The } \\
\text { prototype } \\
\text { stratum }\end{array}$ & 22.0 & $23.5^{\circ}$ & 28 & 22.3 \\
$\begin{array}{l}\text { The model } \\
\text { stratum }\end{array}$ & 1.1 & $23.5^{\circ}$ & 1.4 & 22.3 \\
$\begin{array}{l}\text { Similarity } \\
\text { ratio }\end{array}$ & $1: 20$ & $1: 1$ & $1: 20$ & $1: 1$ \\
\hline
\end{tabular}

TABLE 3: Depths of slits in test models.

\begin{tabular}{lcc}
\hline $\begin{array}{l}\text { Bending } \\
\text { stiffness } /\left(\mathrm{N} \cdot \mathrm{m} \cdot \mathrm{rad}^{-1}\right)\end{array}$ & $\begin{array}{c}\text { Equivalent slit depth } \\
\text { in prototype/mm }\end{array}$ & $\begin{array}{c}\text { Equivalent slit depth } \\
\text { in prototype of } \\
\text { model } / \mathrm{mm}\end{array}$ \\
\hline $\begin{array}{l}2.0 \times 10^{7} \text { (positive } \\
\text { bending) }\end{array}$ & 240 & $\begin{array}{c}12 \text { (tunnel } \\
\text { crown/tunnel } \\
\text { bottom) }\end{array}$ \\
$\begin{array}{l}2.6 \times 10^{7} \text { (negative } \\
\text { bending) }\end{array}$ & 200 & $\begin{array}{c}10 \text { (left/right side } \\
\text { lumbers) }\end{array}$ \\
\hline
\end{tabular}

material made of water, gypsum, and diatomite with the ratio of $1: 1.40: 0.1$, and the ring direction main reinforcement employs the fine iron with the diameter of $\varphi 1.2 \mathrm{~mm}$ to model. The material of the secondary lining is C30 plain concrete, which uses the composite material made of water and gypsum with the ratio of $1: 1.40$, and is added through the cast-inplace concrete. Slits are cut with specific depth in the joint location to weaken the flexural stiffness, which is a way to simulate the transverse joints, and the slits' depth is calculated on the basis of the equivalent principal of the prototype joints' flexural ability, which can be seen in Table 3. As there is tiny dislocation in the longitudinal joint parts of the segment in the practical engineering, steel wire is used with specific diameter in the section of the longitudinal joint linking to simulate the longitudinal joint. Steel wire with the diameter of $4 \mathrm{~mm}$ and length of $40 \mathrm{~mm}$ is employed in this test. The segment lining model and double lining after casting the secondary lining can be seen in Figure 9.

The electric resistance strain gauges are laid out in a transverse direction inside and outside the segment lining and secondary lining, and the test employs the electric resistance strain indicator to test the values of the gauges. The structural internal force of the segment lining and secondary lining could be calculated based on the values of gauges.

Based on the calculating results of the section, the test takes the vertical soil pressure of the section (the loading direction $Y$ of the test) as the uniform soil pressure, and the value is $285.3 \mathrm{kN} / \mathrm{m}$; the horizontal earth pressure (the loading direction $X$ of the test) is also taken as the uniform soil pressure, and the value is $112.5 \mathrm{kN} / \mathrm{m}$. The external load of Model I, Model II, and the improved model is in accord with the test, and the lining beam element amount of these two kinds of numerical models is 400 . According to Formulas 
TABLE 4: Comparison on extreme internal forces between numerical and test results.

\begin{tabular}{|c|c|c|c|c|c|c|c|c|}
\hline \multirow[b]{2}{*}{ Subject } & \multicolumn{2}{|c|}{ Model I } & \multicolumn{2}{|c|}{ Mode II } & \multicolumn{2}{|c|}{ The improved model } & \multicolumn{2}{|c|}{ Similarity model test } \\
\hline & $\begin{array}{l}\text { Maximum } \\
\text { value }\end{array}$ & $\begin{array}{l}\text { Minimum } \\
\text { value }\end{array}$ & $\begin{array}{l}\text { Maximum } \\
\text { value }\end{array}$ & $\begin{array}{l}\text { Minimum } \\
\text { value }\end{array}$ & $\begin{array}{l}\text { Maximum } \\
\text { value }\end{array}$ & $\begin{array}{l}\text { Minimum } \\
\text { value }\end{array}$ & $\begin{array}{l}\text { Maximum } \\
\text { value }\end{array}$ & $\begin{array}{l}\text { Minimum } \\
\text { value }\end{array}$ \\
\hline \multicolumn{9}{|c|}{ Bending moment $(\mathrm{kN} \cdot \mathrm{m})$} \\
\hline Segment lining & 585.65 & -639.55 & 603.44 & -636.72 & 627.35 & -641.52 & 663.74 & -635.67 \\
\hline Secondary lining & 163.47 & -144.32 & 195.42 & -192.54 & 178.48 & -162.88 & 188.54 & -148.87 \\
\hline \multicolumn{9}{|l|}{ Axial force $(\mathrm{MN})$} \\
\hline Segment lining & -10.98 & -4.65 & -12.03 & -5.97 & -11.67 & -4.75 & -10.28 & -5.24 \\
\hline Secondary lining & -2.89 & -1.45 & -2.32 & -0.92 & -2.78 & -1.22 & -2.44 & -1.07 \\
\hline
\end{tabular}

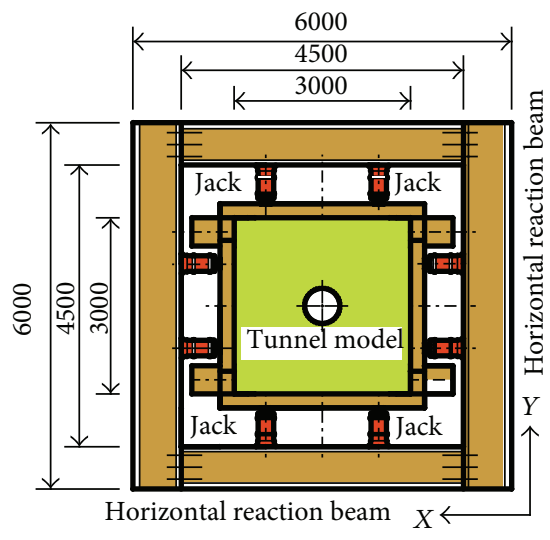

(a) Plan

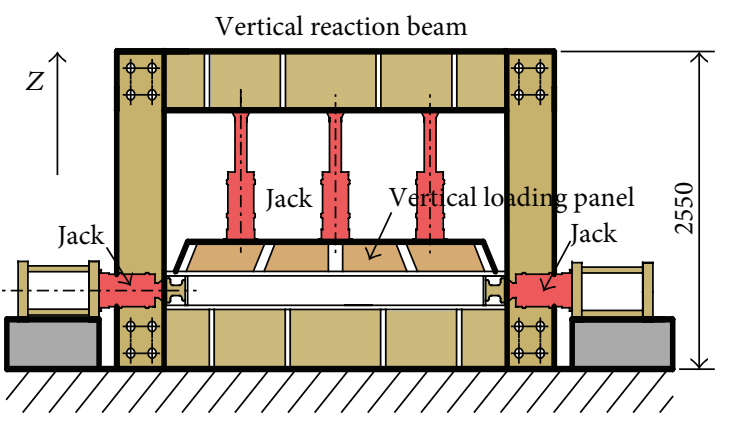

(b) Elevation

FIGURE 7: Sketch of shield tunnel-ground complex simulation equipment (unit: mm).

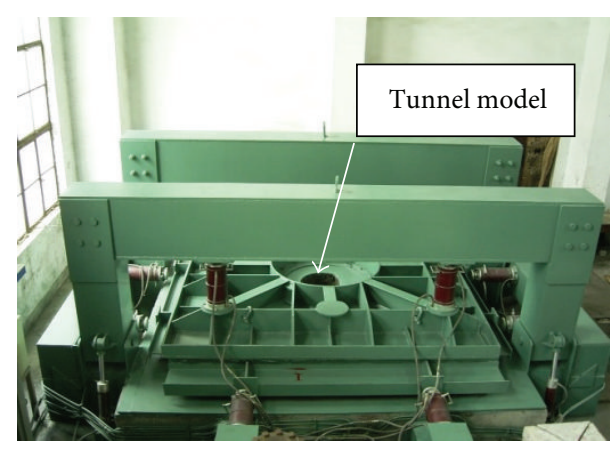

Figure 8: Tunnel-ground complex simulation equipment.

(1a) and (1b) to (5), the radial compression bar and tangential spring element amount of the junction surface are both 400 , and their stiffness is $7.28 \times 10^{6} \mathrm{kN} / \mathrm{m}$ and $3.03 \times 10^{6} \mathrm{kN} / \mathrm{m}$, respectively. The radial compression bar and tangential spring stiffness of the ground's contact surface are $4.41 \times 10^{5} \mathrm{kN} / \mathrm{m} / n$ and $2.21 \times 10^{5} \mathrm{kN} / \mathrm{m} / n$, respectively, and $n$ is the tangential compression bar amount of the contact surface.

\section{Analysis of Results and Discussion}

3.1. Results after Comparison. As the friction coefficient value of the junction surface of Model III is difficult to determine, it will only compare the result of test with the results of Model I, Model II, and the improved model here. The segment lining joint stiffness of Model I, Model II, and the improved model is in accord with that of test prototype. The measured internal force of the model test and the calculating internal force of the numerical models are shown in Figure 10, and the extreme internal force values can be seen in Table 4 . The bending moment takes the external tensile as the positive value and the axial force takes the compression as the positive value.

From Figure 10 it can be seen that the bending moment distribution and axial force distribution of the segment lining and secondary lining in the model test and improved numerical model are similar, and the extreme values of bending moment and axial force on the segment lining and secondary lining are relatively close as well. For instance, the segment lining bending moment's maximum values from the similarity model test and improved numerical model are $663.74 \mathrm{kN} \cdot \mathrm{m}$ and $627.35 \mathrm{kN} \cdot \mathrm{m}$, respectively, and the minimum values are $-635.67 \mathrm{kN} \cdot \mathrm{m}$ and $-641.52 \mathrm{kN} \cdot \mathrm{m}$, respectively. The secondary lining maximum values from the model 


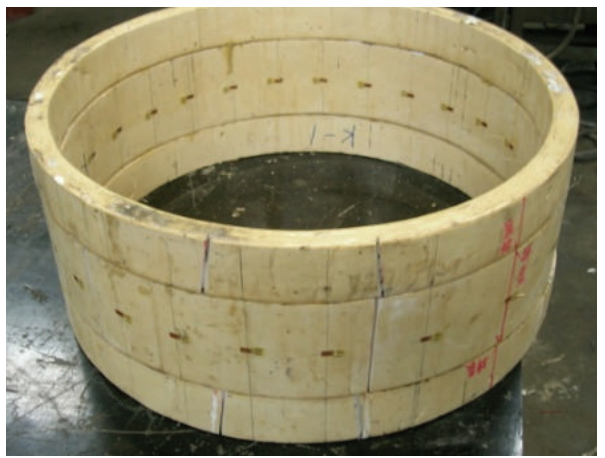

(a) Segment lining

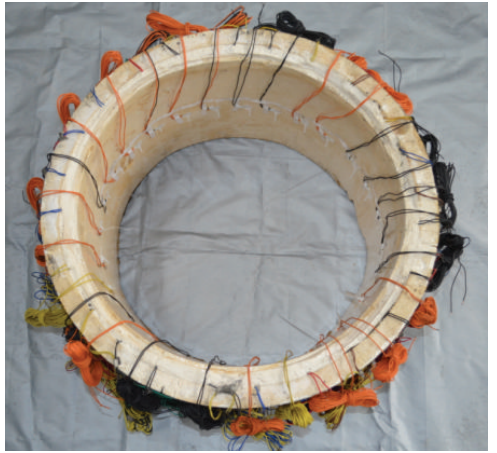

(b) Segment lining and secondary lining

Figure 9: Test model of double lining.

test and the improved numerical model are $188.54 \mathrm{kN} \cdot \mathrm{m}$ and $178.48 \mathrm{kN} \cdot \mathrm{m}$, respectively, and the minimum values are $-148.87 \mathrm{kN} \cdot \mathrm{m}$ and $-162.88 \mathrm{kN} \cdot \mathrm{m}$, respectively. Corresponding to the similarity model test, the relative error of the bending moment's extreme value is within $\pm 10.0 \%$. According to the same analysis, the relative error of the axial force's extreme value is within $\pm 12.5 \%$. It indicates that using the improved numerical model to analyze the mechanical behavior of double lining is feasible. The bending moment and axial force from the improved numerical model and similarity model test have some difference as well. The reason for this difference may be due to the fact that the improved numerical model is a model of load application to structure directly, but the model test is a model of load application to structure through stratum. Even though the imposed external load between the two is the same, the actual bearing load of the structure in the improved model has some difference with that of the structure in the model test. Meanwhile, adopting the imposed constraint from the radial and tangential ground spring will make some errors to the imposed constraint from similar soil material to the structure in the test.

According to Figure 10, it also can be seen that the internal force distribution of Model I and Model II is close to the improved model too. The reason is that Model I and Model II employ the same stiffness calculating methods and parameters, which match the improved model's junction surface and the contact surface. But in Figure 10(a), from the bending moment's enlarged drawing in the parts of the crown and haunch of the segment lining, it can be established that there still exist differences of internal force distribution among Model I, Model II, and the improved model. The bending moment of numerical Model I is presented with the zigzag shape in detailed parts of the crown, and the bending moment of numerical Model II has some relatively large fluctuations in the crown and haunch parts as well. And there is precisely the abrupt change of bending moment caused by the radial beam element of the junction surface in Model I and the radial spring transmitting tension in Model II, although the phenomenon should not really exist. When laying the waterproof layer between the segment lining and the secondary lining, which cannot pass tension completely, carrying on the mechanical behavior analysis will cause more obvious error when using Model I and Model II.

When there is a relatively large difference between the vertical and horizontal loads, the deformation of segment lining and secondary lining will no longer be synchronous in some parts, where the junction surface will separate inevitably. And laying the waterproof layer between the segment lining and the secondary lining, the junction surface could not transfer tension. Under these conditions, the values from Model I and Model II are removed from reality. At this time, using the improved model will avoid this phenomenon effectively and acquire the internal force distribution much closer to the model test. Therefore, the improved model should be selected as the numerical analysis model of the double lining because of its greater rationality.

3.2. Application and Discussion of Improved Model. To know more about the mechanical behavior of double lining, taking the Huangpu River Tunnel in the Shanghai-Nantong Railway in China as the example here, the improved numerical model is adopted to simulate and analyse. The total length of the Huangpu River Tunnel is $8.3 \mathrm{~km}$, and the internal and external diameters are $8.74 \mathrm{~m}$ and $10.3 \mathrm{~m}$. The segment lining employs a reinforced concrete structure of the " $5+2+1$ " segment block form and universal segment lining with a thickness of $0.48 \mathrm{~m}$. The secondary lining is made up of a cast-in-place reinforced concrete structure with a thickness of $0.3 \mathrm{~m}$. The basic material parameters of the double lining can be seen in Figure 5.

The double lining structure schematic is shown as in Figure 11(a), and the load distribution is shown in Figure 11(b). The earth pressure adopts the Terzaghi Theory to calculate: $p_{1}$ and $p_{2}$ are the pressures of the covering soil and reaction force of the bottom ground, respectively, $q_{1}$ and $q_{2}$ are the lateral earth pressures of tunnel crown and tunnel bottom, respectively, and $w_{1}$ and $w_{2}$ are the water pressures of the tunnel crown and tunnel bottom, respectively. A section with a buried depth of $20.51 \mathrm{~m}$ and the water head of $19.75 \mathrm{~m}$ is chosen to analyse. At this time, $p_{1}, p_{2}, q_{1}, q_{2}, w_{1}$, and $w_{2}$ are $880.7 \mathrm{kN} / \mathrm{m}, 638.1 \mathrm{kN} / \mathrm{m}, 442.5 \mathrm{kN} / \mathrm{m}, 1162.3 \mathrm{kN} / \mathrm{m}$, $2051.3 \mathrm{kN} / \mathrm{m}$, and $3081.1 \mathrm{kN} / \mathrm{m}$, respectively. 


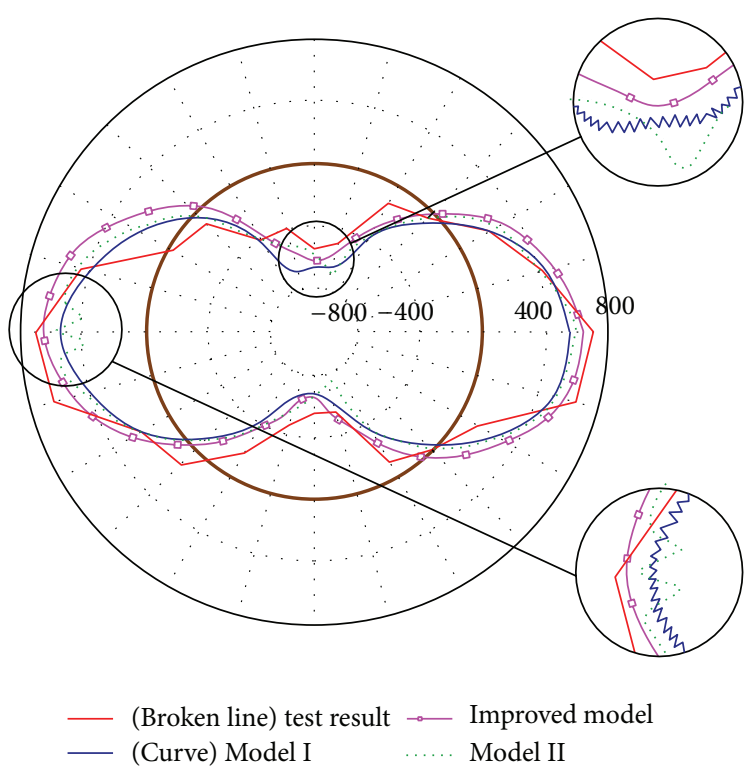

(a) Bending moment of segmental lining (unit: $\mathrm{kN} \cdot \mathrm{m}$ )
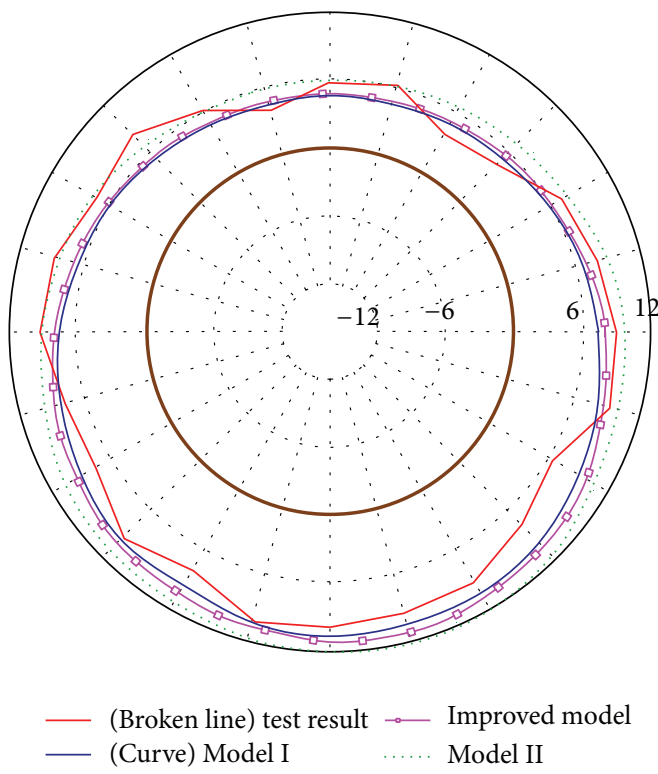

(c) Axial force of segmental lining (unit: MN)

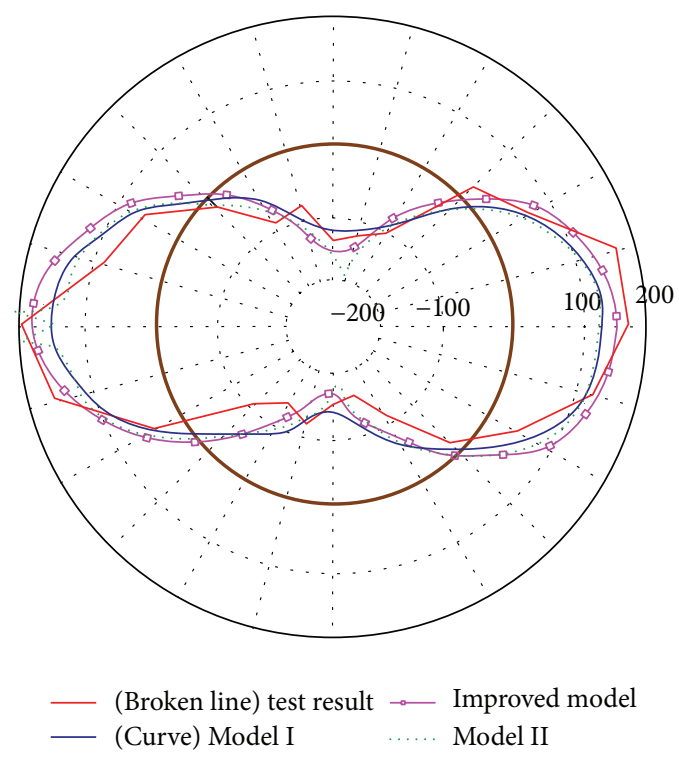

(b) Bending moment of secondary lining (unit: $\mathrm{kN} \cdot \mathrm{m}$ )

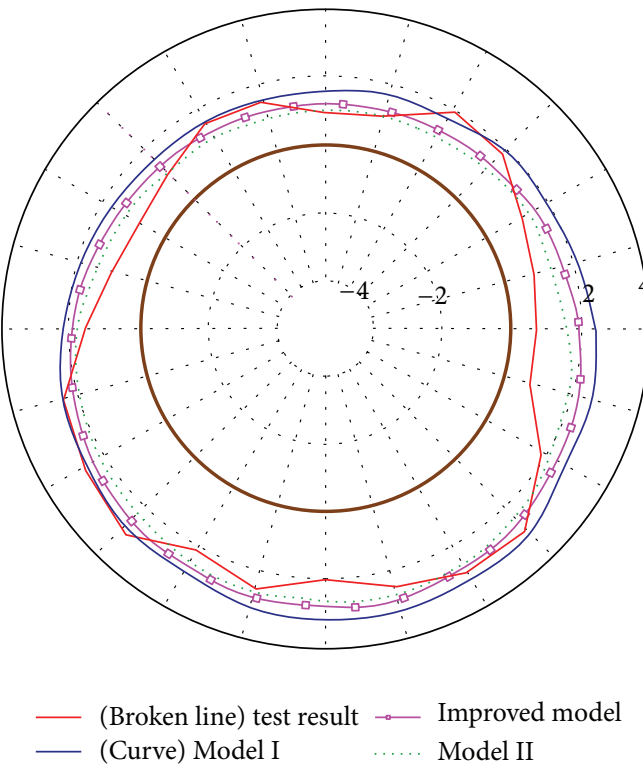

(d) Axial force of secondary lining (unit: $\mathrm{MN}$ )

FIgURE 10: Diagrams for tested values and calculated values of internal forces in lining.

The thickness of the segment lining and the secondary lining in the models is calculated according to its actual thickness. The amount of the junction surface compression bar, the amount of the junction surface tangential spring, the stratum compression bar amount, and the stratum tangential spring amount all are 400. Putting the parameters in Table 5 into Formula (2), it could be calculated that the radial compression bar stiffness of the junction surface is 6.78 $\times 10^{6} \mathrm{kN} / \mathrm{m}$ and the tangential spring stiffness is $2.82 \times$ $10^{6} \mathrm{kN} / \mathrm{m}$. According to the geological data, the ground radial resistance coefficient is $7 \mathrm{MPa} / \mathrm{m}^{3}$. According to (5), the radial compression bar stiffness of the contact surface can be calculated: $2.26 \times 10^{5} \mathrm{kN} / \mathrm{m} / n$, where $n$ is the amount of the
TABLE 5: Material parameters of double linings.

\begin{tabular}{lcccc}
\hline Subject & Material & $\begin{array}{c}\text { Elastic } \\
\text { modulus } \\
(\mathrm{kPa})\end{array}$ & $\begin{array}{c}\text { Density } \\
\left(\mathrm{kg} / \mathrm{m}^{3}\right)\end{array}$ & $\begin{array}{c}\text { Poisson's } \\
\text { ratio }\end{array}$ \\
\hline $\begin{array}{l}\text { Segment } \\
\text { lining }\end{array}$ & $\begin{array}{c}\text { C50 } \\
\text { concrete } \\
\text { C30 }\end{array}$ & $3.45 \times 10^{7}$ & 2450 & 0.2 \\
$\begin{array}{l}\text { Secondary } \\
\text { lining }\end{array}$ & $\begin{array}{c}\text { concrete } \\
\text { con }\end{array}$ & $3.00 \times 10^{7}$ & 2450 & 0.2 \\
\hline
\end{tabular}

ground contact surface radial compression bar, taking half of the radial stiffness as the stiffness of tangential spring. 


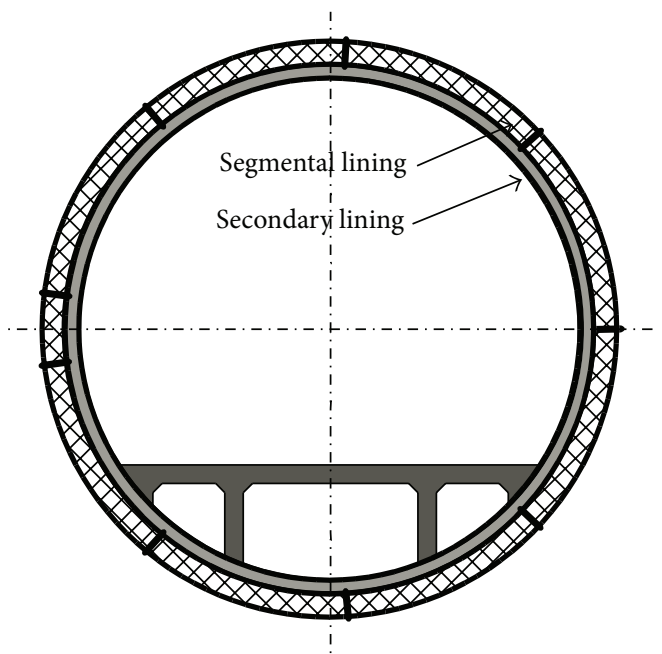

(a) Sketch of shield tunnel with double lining

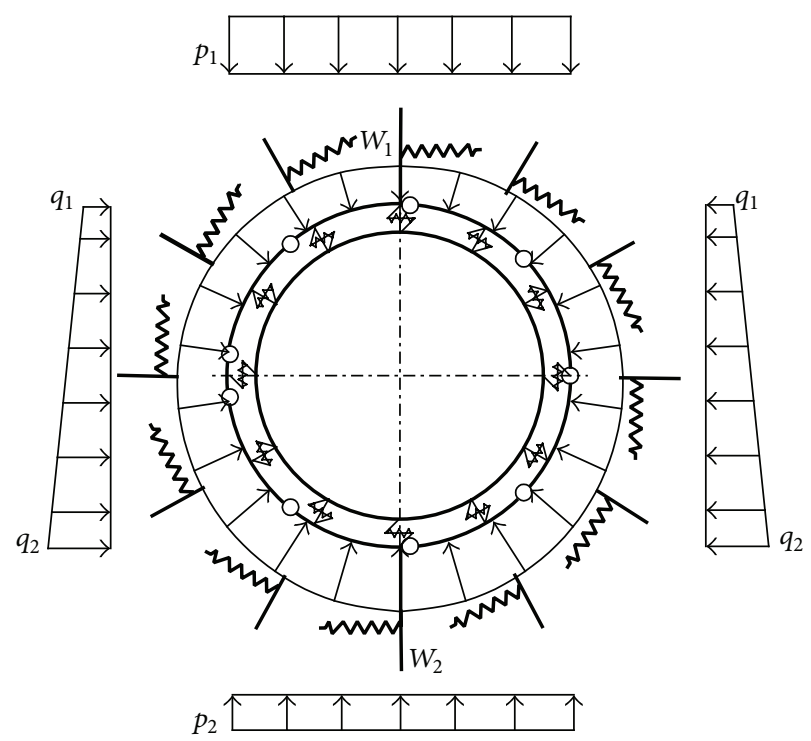

(b) Load condition

FIGURE 11: Schematic diagram of double linings and its load case.

According to the relevant research results $[17,18]$, the stiffness of the tension and compression spring of the segment joint may be taken as $4.14 \times 10^{9} \mathrm{kN} / \mathrm{m}$ and the shear spring stiffness as $1.34 \times 10^{9} \mathrm{kN} / \mathrm{m}$. The transversal flexural stiffness of the segment joint may be taken as $4 \times 10^{5} \mathrm{kN} \cdot \mathrm{m}$ when traction is in the internal surface of the lining and $2.4 \times$ $10^{5} \mathrm{kN} \cdot \mathrm{m}$ when traction is in the outside surface.

\subsubsection{The Discussion of Junction Surface Element Amount.} Theoretically, the radial compression bar and tangential spring amount of the junction surface (i.e., the element amount of the junction surface, the same below) influences the stiffness of the single radial compression bar and tangential spring. Obviously, the larger the amount, the smaller the area corresponding to the single radial compression bar and tangential spring, and the corresponding stiffness is smaller. Different junction surface quantities must be set in order to optimize and analyse, so as to determine the reasonable amount of tangential spring and radial compression bar. Setting the radial compression bar and tangential spring amount between the segment lining and the secondary lining as $20,40,100,200,400,1000$, and 2000, respectively, and also comparing the maximum deformation of the segment lining and the secondary lining, the extreme value of the bending moment (the bending moment is positive when traction is in the outside surface, the opposite is negative, the maximum is the positive peak, and the minimum is the negative peak, the same below) and the extreme value of the axial force (the maximum value of the axial force is the maximum pressure value, and the minimum value is the minimum pressure value, the same below) can be noted. The calculated results can be seen in Figure 12.

Figure 12 shows that, with the constant increase of the junction surface element amount, the maximum deformation value of the secondary lining and segment lining will eventually trend towards convergence. And it will be basically steady when the element amount of the junction surface is more than 400; when the junction surface amount is less than 100 , the lining bending moment extreme value will be more influenced by the element amount. But when the element amount is more than 400 , the bending moment extreme values of the secondary lining or of the segment lining will both achieve basic stability. Meanwhile, when the junction surface element amount is less than 400, the axial force extreme value of the segment lining will increase with the element amount, and the axial force extreme value of secondary lining will decrease gradually with the element amount. But when the element amount is more than 400 , the axial force extreme value of these two will both be basically steady. The aforementioned phenomenon shows that the junction surface element amount could not be chosen optionally because the amount will have a large influence on the analysis result. And among the different engineering objects, their junction surface element amount has a reasonable range.

As far as the double lining of the Huangpu River Shield Tunnel is concerned, comprehensively considering all the factors including the maximum deformation value, the bending moment extreme value, and axial force extreme value of the segment lining and the double lining, a conclusion can be drawn that it is appropriate to take 400 as the junction surface amount. The discussion below will be based on the condition of 400 radial compression bars and 400 tangential springs.

3.2.2. Mechanical Behavior of Double Lining. Based on the radial compression bar and tangential spring amount of the junction surface above, and with a focus on the Huangpu River Tunnel, the mechanical behavior analysis of the different segment lining thickness and different double lining thickness within the same external load is carried out. 


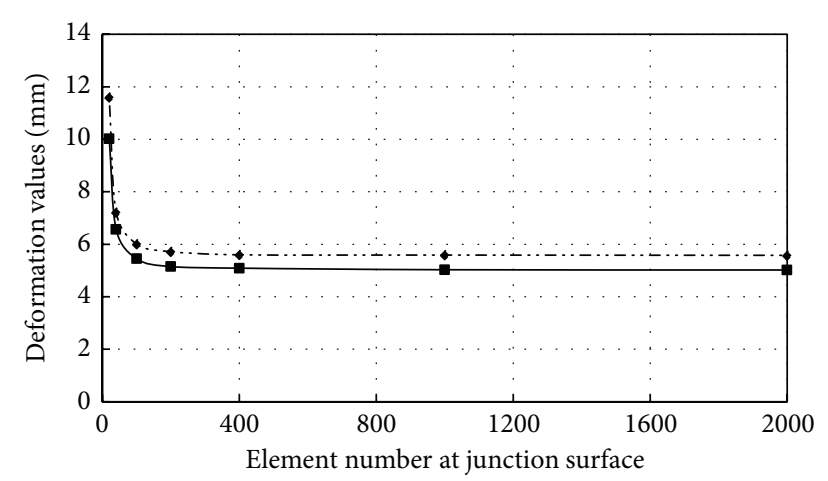

- - Segmental lining

- Secondary lining

(a) The max deformation

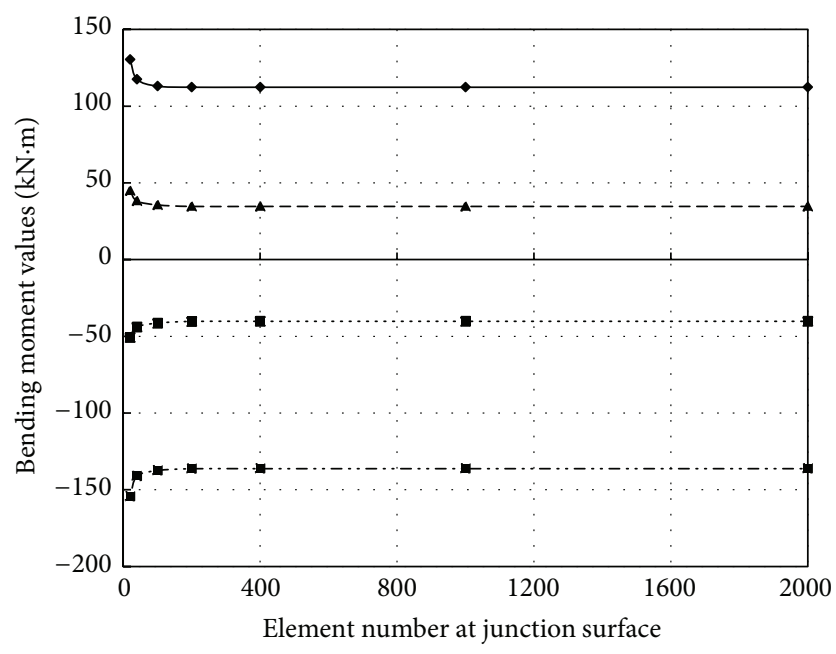

- The max bending moment of segmental lining

$\rightarrow-$. The min bending moment of segmental lining

- - The max bending moment of secondary lining

-... The min bending moment of secondary lining

(b) The extreme bending moment

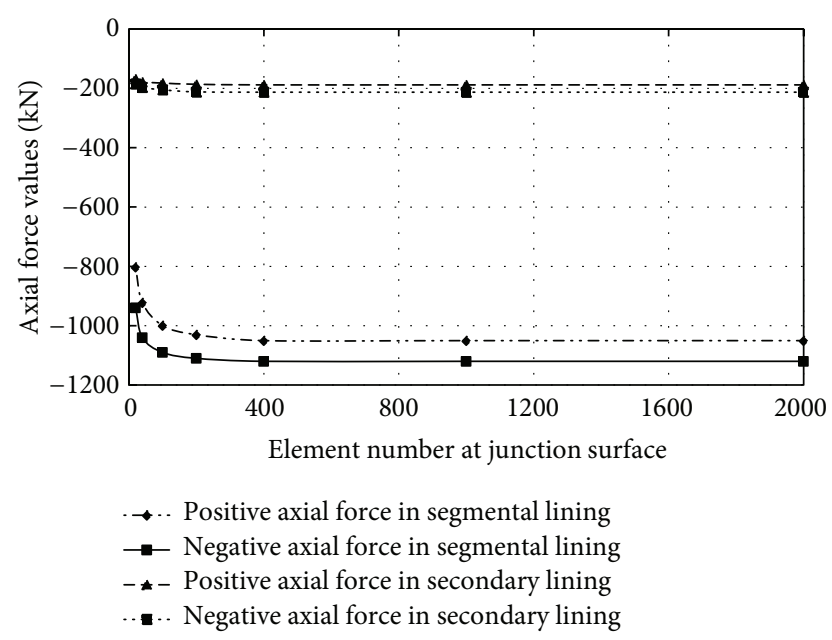

(c) The extreme thrust force

FIGURE 12: The influence of element number at junction surface on inner forces of double lining.
(1) Different thickness of segment lining: the thickness of the secondary lining is $0.30 \mathrm{~m}$, and the thicknesses of the segment lining are $0.30 \mathrm{~m}, 0.40 \mathrm{~m}, 0.50 \mathrm{~m}, 0.60 \mathrm{~m}$, and $0.70 \mathrm{~m}$, respectively, and the thicknesses of the corresponding double lining are $0.60 \mathrm{~m}, 0.70 \mathrm{~m}, 0.80 \mathrm{~m}, 0.90 \mathrm{~m}$, and $1.00 \mathrm{~m}$, respectively. The bending moment extreme values of the double lining (the sum of the bending moment of the segment lining and the secondary lining in the same section within a single ring breadth with $2 \mathrm{~m}$, the same below) and the corresponding bending moment of the segment lining can be seen in Figure 13(a) and Table 6. The maximum and minimum axial force of the double lining and segment lining (the sum of axial force of the segment lining and secondary lining in the same section within a single ring breadth with $2 \mathrm{~m}$, the same below) and the corresponding axial force of the segment lining can be seen in Figure 13(b) and Table 7.

Figure 13(a) shows that, on condition that the secondary lining has a constant or specific thickness, with the segment lining thickness increasing constantly, the absolute values of the maximum and minimum bending moment of the double lining both tend to increase, and the absolute values of bending moments for the segment lining at each corresponding section increase as well. From Figure 13(b), it can be seen that the maximum and minimum axial force of the double lining has little change with the increase of the segment lining thickness, but each axial force of the segment lining at a corresponding section obviously increases.

From Tables 6 and 7, it can be seen that, with the constant increase of the segment lining thickness, the increasing ratio of the bending moment and axial force for the double lining has little relation to the increasing ratio of the double lining thickness. The allocation proportion of the bending moment and axial force between the segment lining and secondary lining has no linear relationship with the ratio of the segment lining and the secondary lining thickness. With the constant increase in the segment lining thickness, the ratio of bending moment and axial force burdened by the segment lining goes up gradually. The allocation proportion of the bending moment of the segment lining at each section of the maximum and the minimum bending moment of the double lining takes a basically consistent ratio, and the allocation proportion of the axial force at each section of the maximum and minimum axial force shows a similar law as well.

(2) Different thickness of secondary lining: the thickness of segment lining is $0.50 \mathrm{~m}$, and the thicknesses of the secondary lining are $0.10 \mathrm{~m}, 0.20 \mathrm{~m}, 0.30 \mathrm{~m}, 0.40 \mathrm{~m}$, and $0.50 \mathrm{~m}$, respectively, and the thicknesses of the corresponding double lining are $0.60 \mathrm{~m}, 0.70 \mathrm{~m}, 0.80 \mathrm{~m}, 0.90 \mathrm{~m}$, and $1.00 \mathrm{~m}$, respectively. Through computing, the maximum and minimum bending moment of double lining and the bending moment of the segment lining at the corresponding section can be seen in Figure 14(a) and Table 8, and the maximum and minimum axial force of the double lining and the axial force of segment lining at the corresponding section can be seen in Figure 14(b) and Table 9.

From Figure 14(a) it can be seen that, on condition that the secondary lining has a specific thickness, with the secondary lining thickness increasing constantly, the absolute 


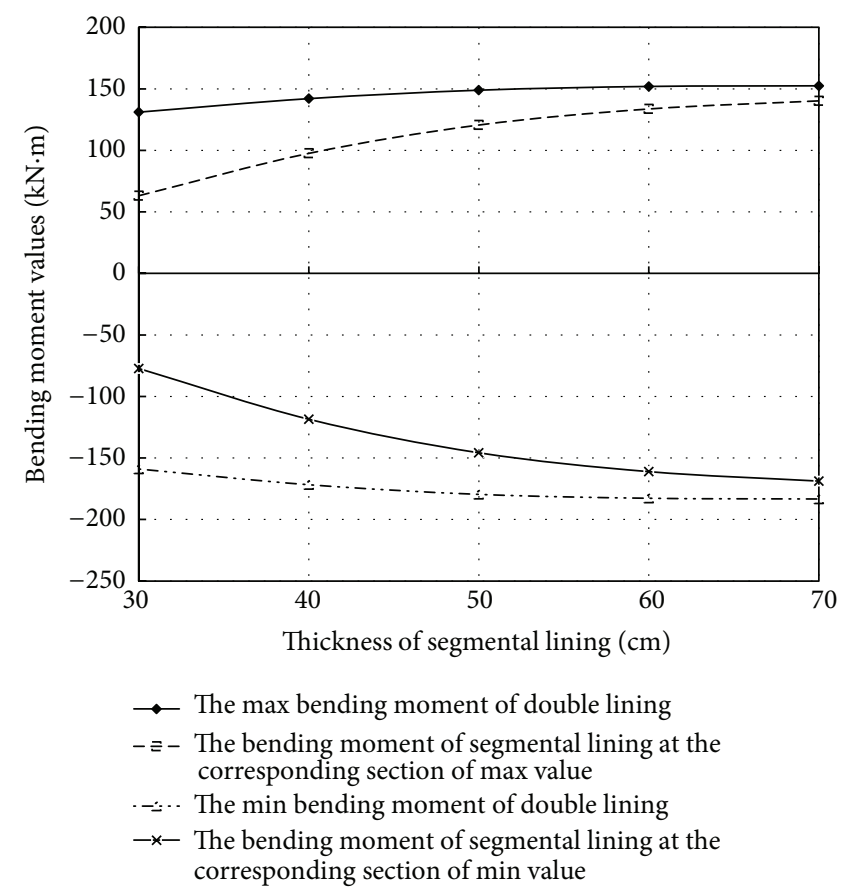

(a) The bending moment

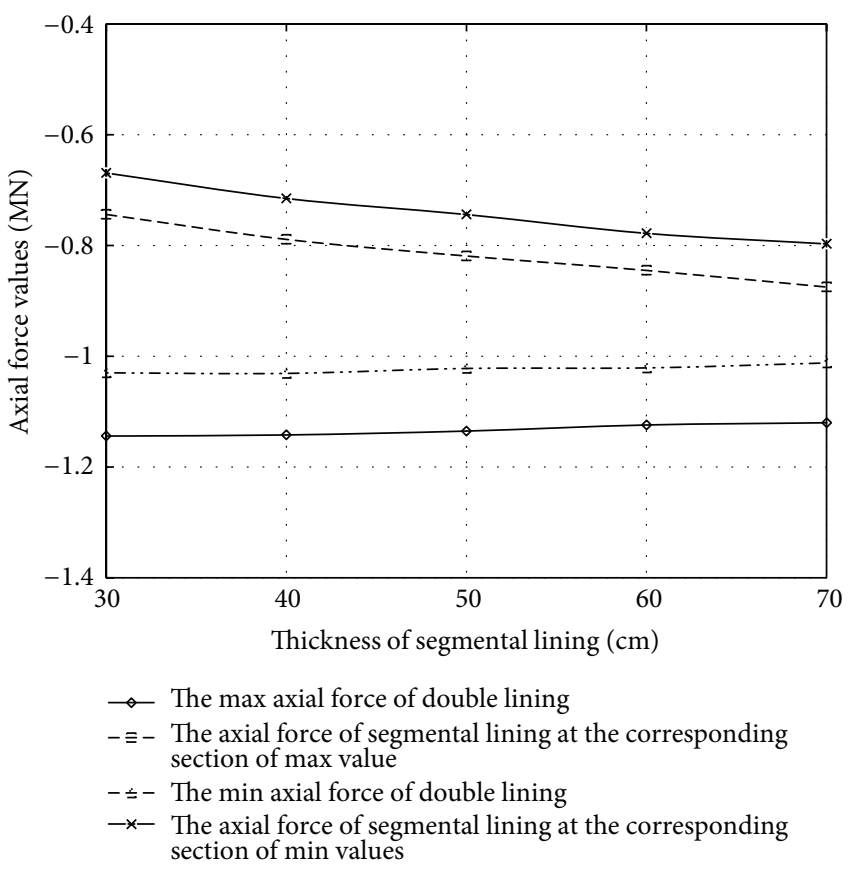

(b) The axial force

FIGURE 13: Numerical results of double lining under different thicknesses of segment lining.

TABLE 6: The bending moments extreme values under different thicknesses of segment lining.

\begin{tabular}{|c|c|c|c|c|c|}
\hline Thickness of segment lining $(\mathrm{cm})$ & 30 & 40 & 50 & 60 & 70 \\
\hline Thickness of double lining (cm) & 60 & 70 & 80 & 90 & 100 \\
\hline The increase ratio of double lining thickness & $100 \%$ & $117 \%$ & $133 \%$ & $150 \%$ & $167 \%$ \\
\hline \multicolumn{6}{|l|}{ The section of maximum bending moment of the double lining } \\
\hline Bending moment of double lining $(\mathrm{kN} \cdot \mathrm{m})$ & 131.047 & 142.037 & 148.896 & 151.945 & 152.454 \\
\hline Bending moment of segment lining at the corresponding section $(\mathrm{kN} \cdot \mathrm{m})$ & 63.178 & 97.604 & 120.650 & 133.701 & 140.300 \\
\hline The allocation proportion of bending moment of segment lining & $48 \%$ & $69 \%$ & $81 \%$ & $88 \%$ & $92 \%$ \\
\hline The increase ratio of bending moment of double lining & $100 \%$ & $108 \%$ & $114 \%$ & $116 \%$ & $116 \%$ \\
\hline \multicolumn{6}{|l|}{ The section of minimum bending moment of the double lining } \\
\hline Bending moment of double lining $(\mathrm{kN} \cdot \mathrm{m})$ & -158.954 & -171.705 & -179.542 & -182.704 & -183.285 \\
\hline Bending moment of segment lining at the corresponding section $(\mathrm{kN} \cdot \mathrm{m})$ & -77.292 & -118.510 & -145.771 & -161.090 & -168.780 \\
\hline The allocation proportion of bending moment of segment lining & $49 \%$ & $69 \%$ & $81 \%$ & $88 \%$ & $92 \%$ \\
\hline The increase ratio of bending moment of double lining & $100 \%$ & $108 \%$ & $113 \%$ & $115 \%$ & $115 \%$ \\
\hline
\end{tabular}

values of the maximum and minimum bending moment of the double lining both tend to increase, but the rate of increase is small. And the absolute value of the maximum and minimum bending moment of the segment lining at the corresponding section tends to decrease. From Figure 14(b), it can be seen that the maximum and minimum axial force of the double lining barely changes with the increase in the secondary lining thickness, but each axial force extreme value of the segment lining at the corresponding section tends to decrease.

From Tables 8 and 9 it can be seen that, with the constant increase of the thickness of the secondary lining, the increasing ratio of bending moment and axial force of the double lining has little relationship with the increasing ratio of the double lining thickness, and the allocation proportion of the bending moment and the axial force between the segment lining and the secondary lining has no linear relationship with the ratio of the segment lining and the secondary lining thickness. With the constant increase in the secondary thickness, the ratio of the bending moment and the axial force that is burdened by the secondary lining decreases quickly. The allocation proportion of the bending moment of the segment lining at each section of the maximum bending moment and the minimum bending moment of the double lining takes a basically consistent ratio, and the same law applies to the axial force as well. 
TABLE 7: The axial force extreme values under different thicknesses of segment lining.

\begin{tabular}{|c|c|c|c|c|c|}
\hline Thickness of segment lining (cm) & 30 & 40 & 50 & 60 & 70 \\
\hline Thickness of double lining (cm) & 60 & 70 & 80 & 90 & 100 \\
\hline The increase ratio of double lining thickness & $100 \%$ & $117 \%$ & $133 \%$ & $150 \%$ & $167 \%$ \\
\hline \multicolumn{6}{|l|}{ The section of maximum axial force of the double lining } \\
\hline Axial force of double lining $(\mathrm{MN})$ & -1.144 & -1.142 & -1.135 & -1.124 & -1.120 \\
\hline Axial force of segment lining at the corresponding section (MN) & -0.744 & -0.789 & -0.819 & -0.845 & -0.875 \\
\hline The allocation proportion of axial force of segment lining & $65 \%$ & $69 \%$ & $72 \%$ & $75 \%$ & $78 \%$ \\
\hline The increase ratio of axial force of double lining & $100 \%$ & $99 \%$ & $99 \%$ & $98 \%$ & $98 \%$ \\
\hline \multicolumn{6}{|l|}{ The section of minimum axial force of the double lining } \\
\hline Axial force of double lining $(\mathrm{MN})$ & -1.030 & -1.031 & -1.022 & -1.021 & -1.012 \\
\hline Axial force of segment lining at the corresponding section (MN) & -0.669 & -0.715 & -0.744 & -0.778 & -0.797 \\
\hline The allocation proportion of axial force of segment lining & $65 \%$ & $69 \%$ & $73 \%$ & $76 \%$ & $79 \%$ \\
\hline The increase ratio of axial force of double lining & $100 \%$ & $99 \%$ & $99 \%$ & $99 \%$ & $98 \%$ \\
\hline
\end{tabular}
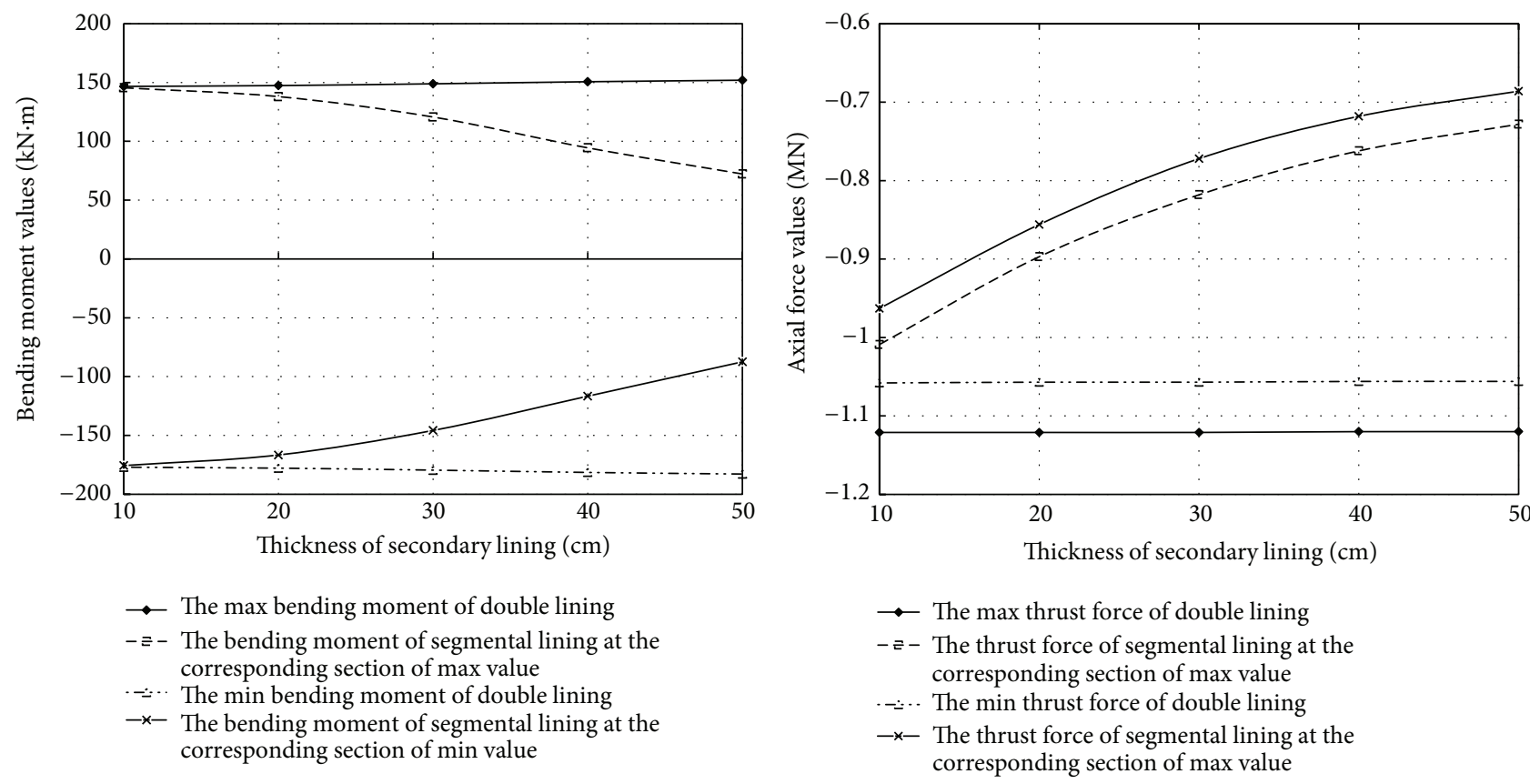

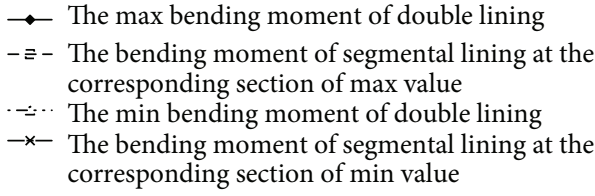

(a) The bending moment

(b) The axial force

Figure 14: Numerical results of double lining under different thicknesses of secondary lining.

\section{Conclusions}

Double lining of an underwater shield tunnel has wide application in the future. Based on the comparative analysis of the existing numerical models of double lining, a new improved numerical model has been presented in this paper. The lining, joint, and junction surface are simulated by beam, spring, and a combination of compression bar and spring. On the basis of employing a similar model test to contrast the existing and the improved models, the advantages of the improved model are compared to the existing model. Eventually, adopting the improved numerical model, the reasonable element amounts of junction surface needed for implementing the accurate analysis of the double lining of the Huangpu River Tunnel are discussed and the mechanic behaviors are studied when changing the thickness of the segment lining and the secondary lining, respectively, at the same load. The main conclusions are listed as follows:

(1) The existing double lining models have the defects of an abrupt change of bending moment, the appearance of radial tensile stress on the junction surface and contact surface, and so forth, and they are inadequate for the task of setting the waterproof layer and the separation of the junction surface.

(2) Through the radial compression bar element, the improved numerical model simulates the radial interaction of the junction surface or the contact surface, 
TABLE 8: The bending moments extreme values under different thicknesses of secondary lining.

\begin{tabular}{|c|c|c|c|c|c|}
\hline Thickness of secondary lining $(\mathrm{cm})$ & 10 & 20 & 30 & 40 & 50 \\
\hline Thickness of double lining $(\mathrm{cm})$ & 60 & 70 & 80 & 90 & 100 \\
\hline The increase ratio of double lining thickness & $100 \%$ & $117 \%$ & $133 \%$ & $150 \%$ & $167 \%$ \\
\hline \multicolumn{6}{|l|}{ The section of maximum bending moment of the double lining } \\
\hline Bending moment of double lining $(\mathrm{kN} \cdot \mathrm{m})$ & 146.689 & 147.398 & 148.896 & 150.660 & 151.945 \\
\hline Bending moment of segment lining at the corresponding section $(\mathrm{kN} \cdot \mathrm{m})$ & 145.480 & 138.001 & 120.650 & 94.474 & 72.271 \\
\hline The allocation proportion of bending moment of segment lining & $99 \%$ & $94 \%$ & $81 \%$ & $62 \%$ & $48 \%$ \\
\hline The increase ratio of bending moment of double lining & $100 \%$ & $100 \%$ & $102 \%$ & $103 \%$ & $104 \%$ \\
\hline \multicolumn{6}{|l|}{ The section of minimum bending moment of the double lining } \\
\hline Bending moment of double lining $(\mathrm{kN} \cdot \mathrm{m})$ & -177.101 & -177.886 & -179.542 & -181.469 & -182.814 \\
\hline Bending moment of segment lining at the corresponding section $(\mathrm{kN} \cdot \mathrm{m})$ & -175.650 & -166.640 & -145.771 & -116.662 & -87.462 \\
\hline The allocation proportion of bending moment of segment lining & $99 \%$ & $94 \%$ & $81 \%$ & $64 \%$ & $48 \%$ \\
\hline The increase ratio of bending moment of double lining & $100 \%$ & $100 \%$ & $101 \%$ & $102 \%$ & $103 \%$ \\
\hline
\end{tabular}

TABLE 9: The axial force extreme values under different thicknesses of secondary lining.

\begin{tabular}{|c|c|c|c|c|c|}
\hline Thickness of secondary lining $(\mathrm{cm})$ & 10 & 20 & 30 & 40 & 50 \\
\hline Thickness of double lining $(\mathrm{cm})$ & 60 & 70 & 80 & 90 & 100 \\
\hline The increase ratio of double lining thickness & $100 \%$ & $117 \%$ & $133 \%$ & $150 \%$ & $167 \%$ \\
\hline \multicolumn{6}{|l|}{ The section of maximum axial force of the double lining } \\
\hline Axial force of double lining (MN) & -1.121 & -1.121 & -1.121 & -1.120 & -1.120 \\
\hline Axial force of segment lining at the corresponding section (MN) & -1.009 & -0.897 & -0.818 & -0.762 & -0.728 \\
\hline The allocation proportion of axial force of segment lining & $90 \%$ & $80 \%$ & $73 \%$ & $68 \%$ & $65 \%$ \\
\hline The increase ratio of axial force of double lining & $100 \%$ & $100 \%$ & $100 \%$ & $100 \%$ & $100 \%$ \\
\hline \multicolumn{6}{|l|}{ The section of minimum axial force of the double lining } \\
\hline Axial force of double lining $(\mathrm{MN})$ & -1.058 & -1.057 & -1.057 & -1.056 & -1.056 \\
\hline Axial force of segment lining at the corresponding section (MN) & -0.963 & -0.856 & -0.772 & -0.718 & -0.686 \\
\hline The allocation proportion of axial force of segment lining & $91 \%$ & $81 \%$ & $73 \%$ & $68 \%$ & $65 \%$ \\
\hline The increase ratio of axial force of double lining & $100 \%$ & $100 \%$ & $100 \%$ & $100 \%$ & $100 \%$ \\
\hline
\end{tabular}

and the link between the bar element and beam element is hinged. Therefore, it can solve the problems of bending moment abrupt change in the junction surface and contact surface and the appearance of radial tensile stress. Through the coupling of node displacement, it demonstrates that the shear force of the junction surface is directly relevant to the shear displacement. Meanwhile, there are definite calculating methods of the element stiffness parameters.

(3) Results of the improved numerical model have better consistency with results from the similar model test, and the element amount of the junction surface and contact surface should be discussed in a specific project, which is the precondition of using the improved model to carry out the double lining mechanical analysis.

(4) With other conditions unchanged, the increase in thickness of the segment lining or the secondary lining will cause the increase of the bending moment of double lining, but this has little influence on the axial force of the double lining. The allocation proportion of the bending moment also has no linear relationship with the ratio of the thickness between the segment lining and the secondary lining.

(5) With the condition that the thickness of the secondary lining remains unchanged, increasing the thickness of the segment lining, the bending moment and its proportion ratio of segment lining increases more at the corresponding section of the maximum and minimum bending moment of the double lining. It shows that the increased part of the bending moment of the double lining mainly depends on the thickened segment lining. And the axial force of segment lining and its proportion have only a small increase.

(6) With the condition that the thickness of the segment lining is unchanged, increasing the thickness of the secondary lining, the bending moment and its proportion ratio of segment lining decreases sharply 
at the corresponding section of the maximum and minimum bending moment of the double lining. It shows that the increased part of the bending moment of the double lining mainly transfers to the thickened secondary lining. The axial force of the segment lining and its proportion have a small decrease.

\section{Conflict of Interests}

The authors declare that there is no conflict of interests regarding the publication of this paper.

\section{Acknowledgments}

This study was supported by the National Natural Science Foundation of China (nos. 51178400, 51278425, and 51408511) and Program for New Century Excellent Talents in University (NCET-11-0713).

\section{References}

[1] H. Diatelmeier, "Design and construction of temporary and permanent lining systems for shield tunnels in Germany," in Proceedings of the Rapid Excavation and Tunneling Conference, vol. 7, pp. 409-422, New Orleans, La, USA, June 1987.

[2] Japan Tunnelling Association, "Challenge and changes: tunnelling activities in Japan 1994," Tunnelling and Underground Space Technology incorporating Trenchless, vol. 10, no. 2, pp. 203215, 1995.

[3] W. H. N. C. van Empel, J. W. Sip, and F. P. Haring, "Design of repair measures of a damaged shield driven tunnel," Tunnelling and Underground Space Technology, vol. 21, no. 3, pp. 338-339, 2006.

[4] J.-M. Zhou, C. He, M.-Q. Xiao, and H.-J. Song, "Field test and numerical simulation of mechanics of segment lining of Shiziyang underwater shield tunnel," Journal of the China Railway Society, vol. 34, no. 7, pp. 115-121, 2012 (Chinese).

[5] K. Uchida, Y. Wasa, and M. Kanai, "Design of the shield tunnel for the trans-Tokyo bay highway," Tunnelling and Underground Space Technology, vol. 7, no. 3, pp. 251-261, 1992.

[6] M. Huang, W. Wang, and G. Zheng, "A review of recent advances in the underground engineering and deep excavations in soft soils," China Civil Engineering Journal, vol. 45, no. 6, pp. 146-161, 2012 (Chinese).

[7] N.-A. Do, D. Dias, P. Oreste, and I. Djeran-Maigre, "2D numerical investigation of segmental tunnel lining under seismic loading," Soil Dynamics and Earthquake Engineering, vol. 72, no. 5, pp. 66-76, 2015.

[8] R. C. Gomes, "Effect of stress disturbance induced by construction on the seismic response of shallow bored tunnels," Computers and Geotechnics, vol. 49, no. 4, pp. 338-351, 2013.

[9] H. El Naggar, S. D. Hinchberger, and M. H. El Naggar, "Simplified analysis of seismic in-plane stresses in composite and jointed tunnel linings," Soil Dynamics and Earthquake Engineering, vol. 28, no. 12, pp. 1063-1077, 2008.

[10] H. Murakami and A. Koizumi, "Behavior of shield segment ring reinforced by secondary lining," Proceedings of JSCE, vol. 12, no. 388, pp. 135-144, 1987 (Japanese).

[11] N. Takamatsu, H. Murakami, and A. Koizumi, "A study on the bending behavior in the longitudinal direction of shield tunnels with secondary linings," in Proceedings of the International Congress on Towards New World in Tunnellings, vol. 5, pp. 277285, ITA, 1992.

[12] H. Zhang, C. Guo, and G. Lu, "Mechanical model for shield pressure tunnel with secondary linings," Journal of Hydraulic Engineering, no. 4, pp. 28-33, 2001 (Chinese).

[13] Working Group No. 2 and International Tunnelling Association, "Guidelines for the design of shield tunnel lining," Tunnelling and Underground Space Technology, vol. 15, no. 3, pp. 303-331, 2000.

[14] The Professional Standards Compilation Group of People's Republic of China, Code for Design of Metro. (GB50157-2003), China Planning Press, Beijing, China, 2003.

[15] S. Abbas, A. M. Soliman, and M. L. Nehdi, "Experimental study on settlement and punching behavior of full-scale RC and SFRC precast tunnel lining segments," Engineering Structures, vol. 72, no. 8, pp. 1-10, 2014.

[16] D. Dias and R. Kastner, "Movements caused by the excavation of tunnels using face pressurized shields-analysis of monitoring and numerical modeling results," Engineering Geology, vol. 152, no. 1, pp. 17-25, 2013.

[17] A. Salemi, M. Esmaeili, and F. Sereshki, "Normal and shear resistance of longitudinal contact surfaces of segmental tunnel linings," International Journal of Rock Mechanics and Mining Sciences, vol. 77, pp. 328-338, 2015.

[18] G. J. Khave, "Delineating subterranean water conduits using hydraulic testing and machine performance parameters in TBM tunnel post-grouting," International Journal of Rock Mechanics and Mining Sciences, vol. 70, no. 9, pp. 308-317, 2014. 

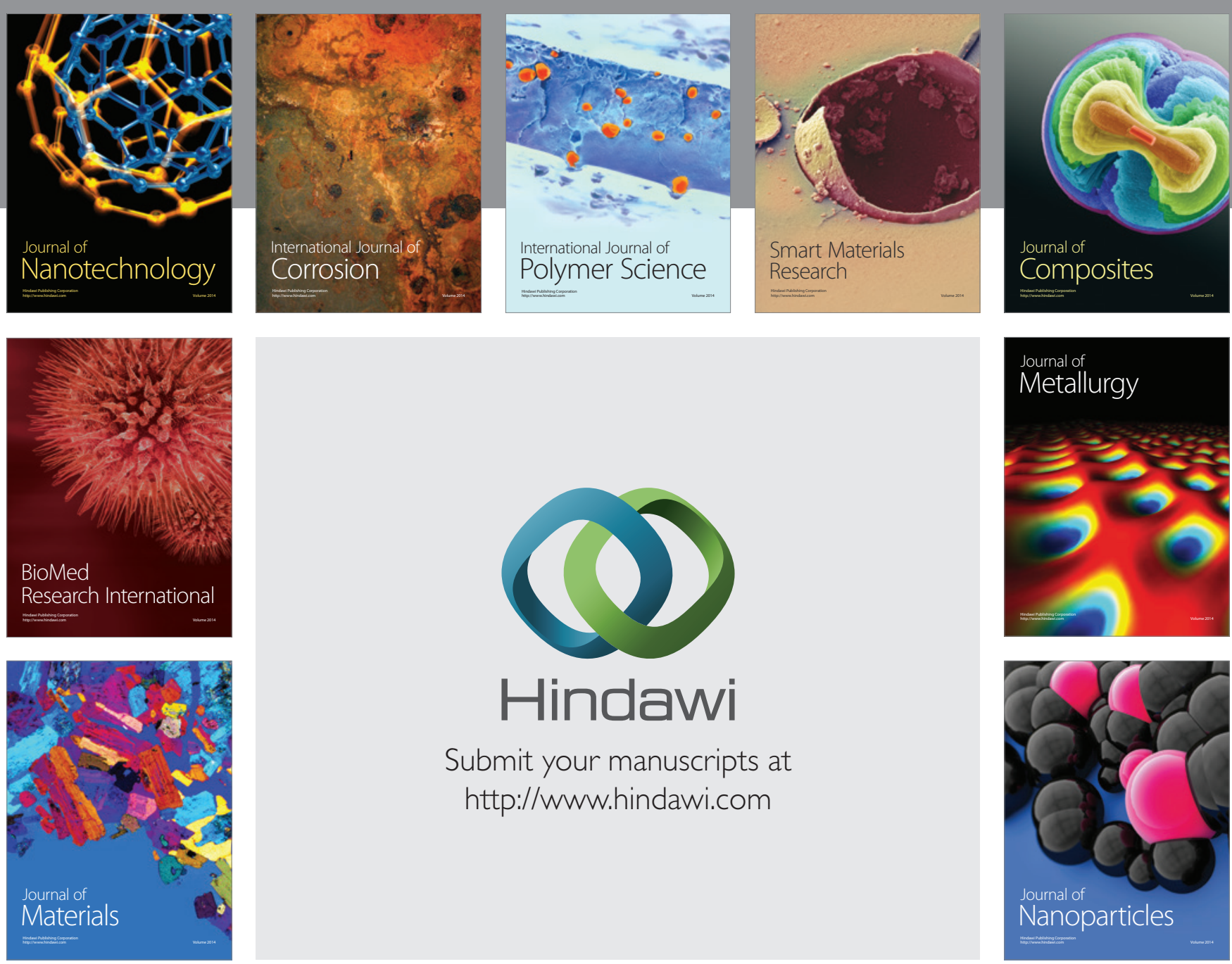

Submit your manuscripts at http://www.hindawi.com
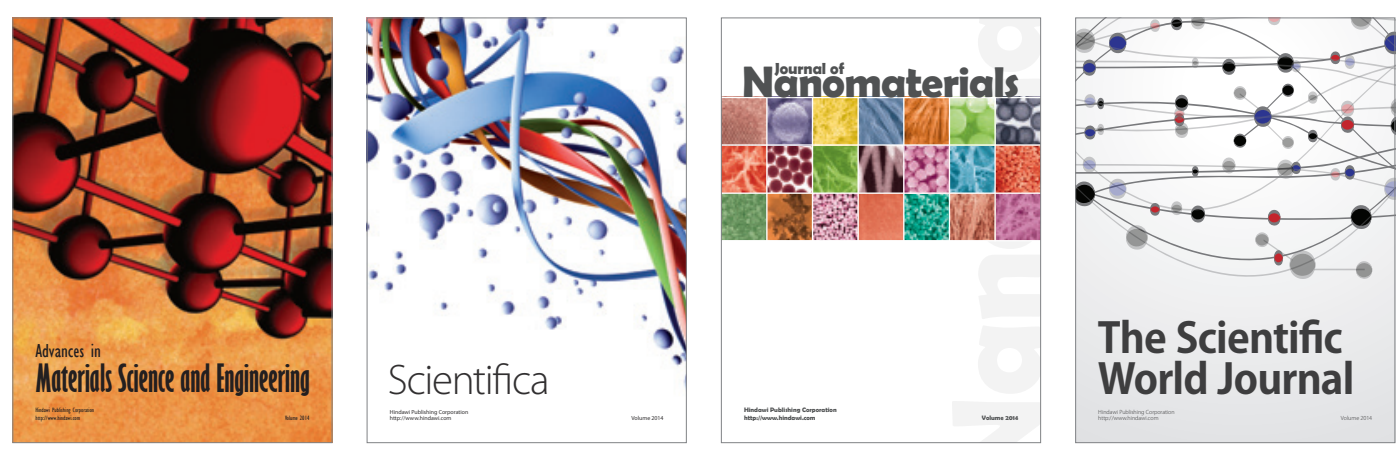

\section{The Scientific World Journal}
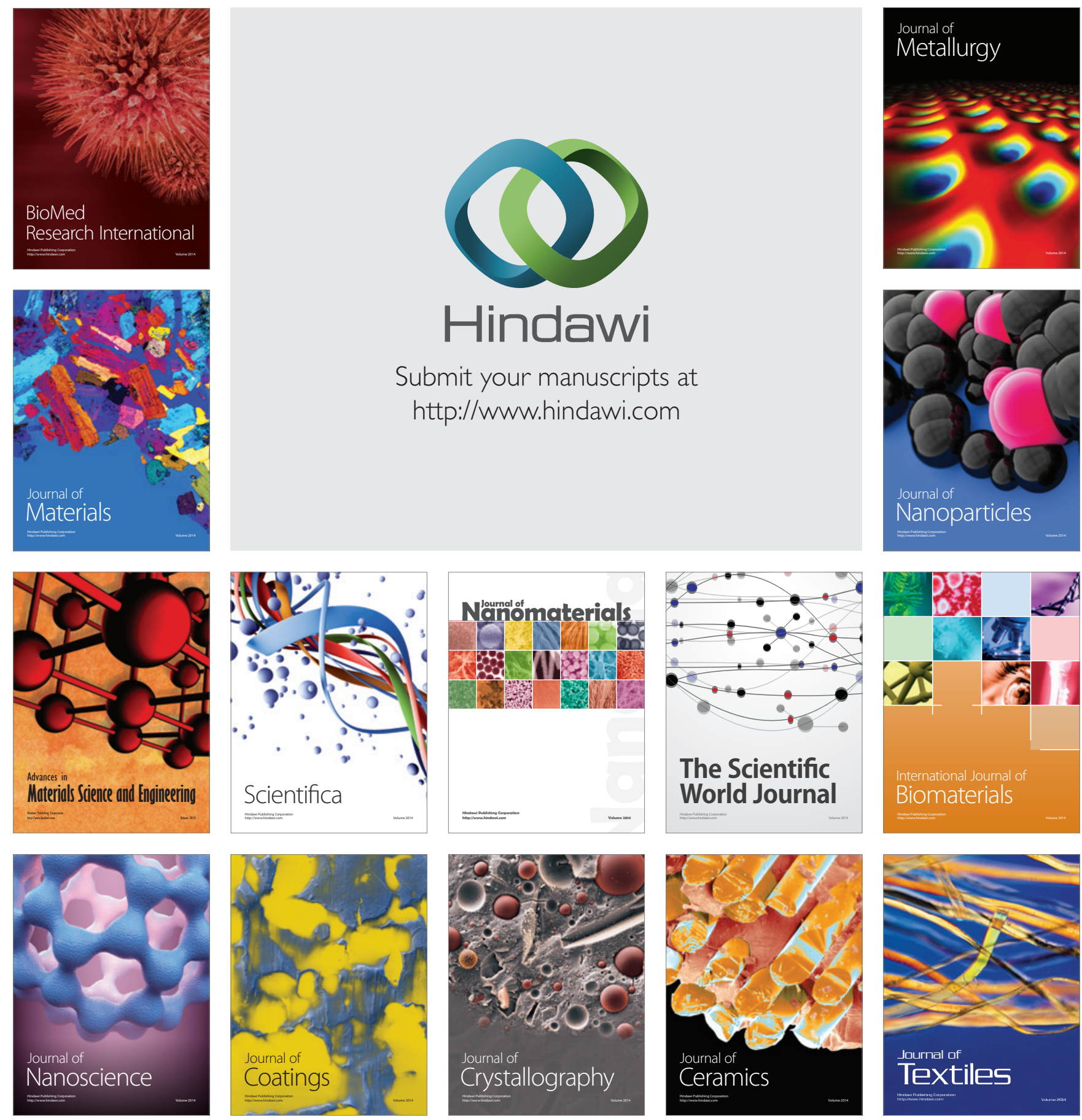